\title{
Augmented reality applied to journalistic information: uses, advantages, drawbacks and challenges
}

DOI: $10.46932 / \mathrm{sfjdv2n1-019}$

Received in: November 1st, 2020

Accepted in: December 30th, 2020

\section{Susana Herrera Damas}

$\mathrm{Ph} \mathrm{D}$ in Audiovisual Communication

Current Institution: Universidad Carlos III de Madrid

Full address: Calle Madrid, 133. 28903 Getafe (Madrid)

E-mail: dherrera@hum.uc3m.es

\section{Rafael Ávila Quintana \\ Master}

Current Institution: Universidad Carlos III de Madrid

Full address: Calle Madrid, 133. 28903 Getafe (Madrid)

E-mail: rafaelavilaquintana@gmail.com

\begin{abstract}
RESUMEN
La realidad aumentada permite superponer elementos virtuales en un escenario real mediante el empleo de tecnologías digitales. Esta innovación está siendo incorporada en diferentes disciplinas como la medicina, la educación, el ámbito militar y también en el sector de los videojuegos. Aplicada al periodismo, permite añadir un nuevo valor a la información haciéndola más completa, enriquecida y espectacular. El objetivo del siguiente texto es analizar sus usos, ventajas, inconvenientes y retos. Para ello hemos llevado a cabo una revisión de la literatura que hemos querido enriquecer con la visión de 6 expertos y profesionales implicados en su realización. Los resultados muestran que junto a innegables usos y ventajas, esta tecnología presenta también inconvenientes y desafíos. Uno de los más evidentes se refiere a la necesidad de dedicar recursos para adaptar los platós y las redacciones, formar a los equipos de grafismo, ajustar de un modo eficiente el criterio periodístico y el técnico, cambiar el proceso de producción de la información y emplear la tecnología con un sentido concreto que evite que quede reducida a un mero ejercicio de estilo. En todo caso, es muy posible que la tecnología $5 \mathrm{G}$ impulse definitivamente la realidad aumentada consiguiendo que su aplicación al periodismo resulte cada vez menos excepcional.
\end{abstract}

Palabras clave: Realidad aumentada, tecnología, periodismo, información, televisión

\section{INTRODUCCIÓN}

Los medios de comunicación en general, pero especialmente la televisión como medio audiovisual han experimentado una gran transformación como consecuencia de la aparición de las nuevas tecnologías (Richeri, 1994). Aunque la televisión en sí misma es una tecnología, ha servido para aglutinar un escaparate de ellas. Entre los hitos tecnológicos, partiendo inequívocamente de su propio nacimiento, podemos destacar la transición de la imagen en blanco y negro al color, la utilización de tecnología de 
transmisión vía satélite o la revolución digital que dejaba atrás la era analógica (Sanz, 2006). Como afirma Pellicer (2013), el binomio comunicación y tecnología es importantísimo en nuestro tiempo. Y es en este mismo tiempo en el que la televisión se ha convertido en el medio hegemónico. El último estadio de ese binomio nos sitúa a las puertas del futuro. Es la realidad aumentada.

La realidad aumentada permite superponer elementos virtuales en un escenario real mediante el empleo de tecnologías digitales. Esta innovación está siendo incorporada en diferentes disciplinas como la medicina, la educación, el ámbito militar y también en el sector de los videojuegos. Aplicada al periodismo, permite añadir un nuevo valor a la información haciéndola más completa, enriquecida y espectacular. Como afirma Bunzi, el periodismo y la realidad aumentada están hechos el uno para el otro.

Aunque se trata de una realidad aún minoritaria, cada vez son más los medios periodísticos de todo el mundo que van incorporando esta tecnología sobre todo para intentar explicar mejor contenidos relacionados con la información política, económica, deportiva, de sucesos, meteorológica o de sociedad. El medio en el que esta innovación resulta más eficaz es la televisión, en la medida que la escenografía virtual que se crea en tiempo real aumenta el valor del relato informativo. En todo caso, también conviene tener en cuenta que una mala praxis puede resultar contraproducente al distraer la atención del espectador que queda atrapado y confundido ante la parafernalia tecnológica.

\section{METODOLOGÍA EMPLEADA}

Esta investigación, de tipo preliminar y exploratoria, forma parte de un estudio más amplio. El propósito de esta contribución es exponer los principales usos, ventajas, límites y desafíos que supone incorporar realidad aumentada a la información periodística. Para ello, la metodología empleada ha consistido en una revisión exhaustiva de la (aún escasa) literatura académica y profesional sobre el tema. En un segundo momento, hemos completado esta revisión con el visionado de cerca de 40 ejemplos de realidad aumentada aplicados a la información periodística por cadenas de televisión de todo el mundo, distinguiendo su finalidad y la sección informativa en la que se ubican.

Enriquecemos el análisis con la realización de seis entrevistas en profundidad con profesionales y expertos. La idea es conocer su percepción respecto a cuáles son las principales aplicaciones, ventajas, límites y desafíos de incorporar esta tecnología para informar de un modo más atractivo que, a su vez, favorezca una comprensión más significativa de la realidad que está siendo representada. Las entrevistas se realizaron mediante un cuestionario digital entre los meses de abril y mayo de 2019. Las preguntas se orientaron a profundizar de manera específica en los siguientes 4 asuntos:

1) ¿Cuáles cree que son los usos más apropiados de aplicar realidad aumentada a la información periodística? 
2) ¿Qué ventajas cree que ofrece?

3) ¿Cuáles considera que son los principales inconvenientes?

4) ¿Qué desafíos plantea esta tecnología para la información periodística?

Los profesionales del ámbito académico a quienes entrevistamos son:

1) Eduardo Herranz: doctor en Ingeniería informática por la Universidad Carlos III de Madrid, donde es profesor asociado. También es profesor visitante en U-Tad para el Certificado de Especialización en Producción VR/AR.

2) Esteban Galán Cubillo: doctor en Comunicación Audiovisual por la Universidad Cardenal Herrera-CEU. En la actualidad, trabaja en el Departamento de Aplicaciones Virtuales de la Televisión Valenciana.

3) Laura Raya González: doctora en Ingeniería Informática por la Universidad Rey Juan Carlos y especializada en Realidad Virtual. Es, además, responsable del Postgrado de Ingeniería en U-tad.

Desde el ámbito profesional de la televisión, mantuvimos entrevistas en profundidad con:

1) César González Antón: director de informativos de La Sexta.

2) Jaime Rull: periodista y creativo de tecnología de realidad aumentada en Atresmedia, y

3) Borja Terán: periodista y crítico especializado en televisión.

\section{MARCO TEÓRICO}

Para definir el concepto de realidad aumentada, consideramos importante partir del "continuo de la virtualidad" (“virtuality continuum") elaborado por Paul Milgram y Fumio Kishino (1994: 1321-1329). Según este concepto, existe una escala que oscila entre lo que se puede definir como totalmente real y lo completamente virtual. Como se puede apreciar en la figura 1, a la izquierda de esta escala apreciamos entornos configurados únicamente por elementos reales. En el lugar opuesto, totalmente a la derecha, encontramos un entorno compuesto tan solo por objetos virtuales; es decir, una simulación gráfica a través de ordenador, por ejemplo. Los objetos reales tienen una existencia objetiva real. Los objetos virtuales existen en esencia o efecto, pero no de una manera formal o real. El concepto realidad aumentada alude a la tecnología que incorpora información digital en un entorno real. De manera primigenia, Milgram y Kishino (1994) partían de una definición operativa de la realidad aumentada como cualquier entorno que "se aumente" mediante el empleo de objetos virtuales. 
Figura 1: Virtuality continuum

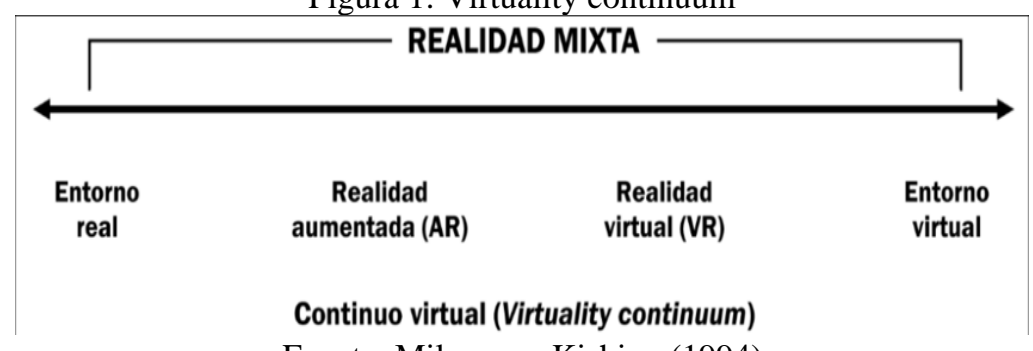

Fuente: Milgram y Kishino (1994)

Antes, Thomas P. Caudell (1992) había desarrollado el término refiriéndose a la utilización de la tecnología para aumentar el campo visual de un usuario con información superpuesta. Azuma (1997), la realidad aumentada permite ver el mundo real con elementos virtuales superpuestos, a los que añade el componente interactivo, el tiempo real y la tecnología en 3D.

En efecto, la realidad aumentada combina elementos virtuales y reales que coexisten en un mismo espacio, es interactiva, en tiempo real y está registrada de un modo tridimensional. La diferencia entre realidad virtual y realidad aumentada reside en el tratamiento que hacen del mundo real. La realidad virtual sumerge al usuario dentro de un mundo virtual que reemplaza completamente el mundo real exterior. La realidad aumentada, en cambio, deja al usuario en el mundo real y superpone en él objetos virtuales, lo que, idealmente, le aporta la ilusión de que los objetos del mundo real y virtual coexisten (Abascal et al., 2001). Siguiendo a Abril, es el entorno dominante el que condiciona un tipo de realidad u otra:

"si el entorno del espacio es dominantemente virtual y se le agregan objetos virtuales y reales, se habla de Realidad Virtual; mientras que, si el entorno dominante es real y se le agregan objetos virtuales, se habla de Realidad Aumentada (Abril, 2012: 2).

En 2015, Prendes Espinosa clasifica la complejidad de esta tecnología a partir de una diferenciación en 4 niveles, según fuese aumentando el grado de inmersión:

i) El nivel 0, denominado physical hyper linking, utiliza códigos de barra (como los qr) o reconocimiento de imágenes. En este nivel los códigos son hiperenlaces a otros contenidos. No existe registro en 3D ni seguimiento de los marcadores

ii) El nivel 1, denominado marker based $A R$, se configura a partir del reconocimiento de patrones $2 \mathrm{D}$ o el reconocimiento de objetos $3 \mathrm{D}$

iii) El nivel 2, al que se refiere como markerless $A R$, funciona a través del uso de GPS, brújulas o acelerómetros de los dispositivos electrónicos. Al ser capaz de determinar la situación y orientación, puede superponer los puntos de interés con las imágenes del mundo real 
iv) Finalmente, en el nivel 3, denominado augmented vision, la realidad aumentada se convierte en visión aumentada y se transforma en una experiencia inmersiva que amplifica las posibilidades para la personalización

Por su parte, Pavlik (2013) se ocupa de la realidad aumentada en su aplicación al periodismo y explica que ésta actúa como un sistema digital en el que el usuario participa en primera persona.

En los últimos diez años, la realidad aumentada ha sido incorporada de modo tímido pero progresivo por algunos de los principales medios periodísticos occidentales. En diciembre de 2009, la revista Esquire editó un número en cuya portada aparecía una fotografía del actor Robert Downey JR con un código de realidad aumentada. El director de la revista, David Granger, explicaba en un vídeo ${ }^{\mathrm{ii}}$ las novedades que suponía esta forma de contar. Al poner el código sobre una cámara, el actor aparecía en un vídeo que se integraba en la propia realidad probándose ropa o hablando al espectador. Este caso ${ }^{\mathrm{iii}}$ es considerado como uno de los detonantes de la realidad aumentada en su aplicación al periodismo (Meneses y Martín, 2013).

Por su parte, la revista inglesa Wallpaper comenzó a ofrecer contenidos de realidad aumentada en enero de $2010^{\text {iv }}$. Desde entonces lo hace con cierta frecuencia y los contenidos para los que recurre a esta tecnología están siempre relacionados con el tema de cabecera (arte, moda o tendencias) (Meneses y Martín, 2013).

La revista de moda italiana Grazia también publicó en su edición británica de marzo de 2010 contenidos 3D y de realidad aumentada. Su editora jefa, Jane Bruton, manifestaba su intención de divertir y asombrar a sus lectores con desfiles de moda, declaraciones de personajes conocidos y reportajes. En concreto, la portada a la que hacemos referencia mostraba a la cantante de Florence and the Machine, Florence Welch, y varios elementos en 3D. El contenido aumentaba para las lectoras a partir de un simple dispositivo móvil ${ }^{v}$ (Meneses y Martín, 2013).

El 20 de agosto de 2010, el suplemento digital SZ Magazine también apostó por la realidad aumentada. Este tipo de contenidos se encontraban en la portada, en la que se mostraba a una mujer ${ }^{\mathrm{vi}}$ que retiraba las manos de su cara al ser enfocada con el móvil, distintas fotografías que se volvían animadas, o las soluciones del crucigrama de la revista (Meneses y Martín, 2013).

En España, las primeras experiencias de realidad aumentada en la industria periodística arrancan en 2010, con el diario El País, a través de su publicación temática El Viajero (Parra, Edo y Marcos, 2017). En abril de este año, El Viajero ${ }^{\text {vii }}$ lanzó una aplicación gratuita, sólo disponible para smartphones iOS y Android, desarrollada por la compañía holandesa Layar. Mediante la cámara de su teléfono móvil, el usuario podía localizar una selección de hoteles y restaurantes, cada uno de ellos con un icono identificativo y una breve descripción. El contenido de la capa de datos era propio del medio y estaba 
basado en las informaciones de la Guía de Hoteles y Restaurantes de El País-Aguilar, del mismo grupo editorial. La aplicación también permitía ver los contenidos de modo tradicional, sin la combinación de objetos reales y contenidos informativos (Parra, Edo y Marcos, 2017).

Asimismo, en septiembre de 2010, la revista de cine Fotogramas lanzó un número especial sobre realidad aumentada, aunque con un sistema ligeramente menos intuitivo y no sustentado en una aplicación móvil. Para poder visionar un total de siete contenidos distribuidos por sus páginas, había que acceder a un enlace web y desde allí enfocar a alguno de los distintos códigos con la cámara web del ordenador. La funcionalidad incluía un breve vídeo que explicaba la iniciativa ${ }^{\text {viii. }}$.

También la revista de moda Elle mostró en su número de diciembre de 2012 varios contenidos con realidad aumentada. El primero de ellos permitía acceder a una sesión de fotos con la periodista Sara Carbonero, que posaba en la portada. Además, el usuario podía aumentar algunos anuncios del interior. Para visualizar el contenido era necesario tener instalada la aplicación PlayAR, disponible para sistemas iOS y Android (Picón, 2014).

En la actualidad, la realidad aumentada no es un elemento extraño para la televisión y ya se incorpora con cierta frecuencia en su escenografía (Azkunaga, Gaztaka y Eguskiza, 2019). Esto ha introducido algunos cambios en la producción y postproducción, ante la necesidad de incluir elementos generados por ordenador (Galán, 2008). Como señala Galán, en televisión la escenografía virtual se utiliza desde los años noventa, cuando se realiza en la versión contraria de la realidad aumentada; es decir, en televisión se superpone imagen real sobre el entorno virtual, mientras que en la realidad aumentada se superpone la imagen virtual sobre la real. En televisión, la realidad virtual se debe entender por tanto como un antecedente de la realidad aumentada.

En 2010, en la sección de tecnología del canal Sky ${ }^{\text {ix }}$, el ingeniero Myles Peyton de la firma Total Immersion llevaba a cabo una demostración con diferentes aplicaciones de la realidad aumentada. También el mundo de la publicidad tanto en medios impresos ${ }^{\mathrm{x}} \operatorname{como}$ en televisión ${ }^{\mathrm{xi}}$ realizó campañas utilizando tecnología aumentada al tiempo que crecía su popularidad.

También es interesante recordar otras dos experiencias que tuvieron lugar en 2012. La primera es esta recreación ${ }^{x i i}$ del mundo natural helado llamada "Frozen Planet" llevada a cabo en el Festival Wildscreen de ese año en el Museo de Bristol. A través de una pantalla, los asistentes podían verse en el hielo, rodeados de pingüinos y otros animales marinos. La siguiente se realizó en una exhibición itinerante sobre naturaleza y fauna salvaje organizada por National Geographic ${ }^{\text {xiii }}$. La firma Appshaker creó una serie de animaciones que permitían al público acercarse a los animales más salvajes del mundo, e incluso “estar" con especies que habitaron el planeta hace millones de años, como los dinosaurios.

Ese mismo 2012 comenzó un proyecto de la firma Jack Tsai Studio ${ }^{\text {xiv }}$. Se trata de un sistema de realidad aumentada que tiene como objetivo mejorar el rendimiento de las noticias en televisión. Mediante 
el reconocimiento de patrones y el seguimiento de marcadores, el presentador puede interactuar con animaciones en tiempo real. El estudio recomendaba ese sistema para noticias en general y de un modo especial para deportes.

Los resultados electorales también han recurrido desde el comienzo y de manera habitual a la realidad aumentada. En 2014, encontramos una de las primeras aplicaciones en el canal NDTV India, un canal de noticias y actualidad. La empresa Vizrt preparó una serie de gráficos tridimensionales para aumentar el plató gracias a una grúa y a un sistema de estudio virtual ${ }^{\mathrm{xv}}$. Por otro lado, en 2015 un acuerdo de colaboración entre la corporación de radiotelevisión pública de Canadá y las compañías Astucemedia, Vizrt y StypeGRIP posibilitó cubrir las elecciones federales de este país con el empleo de esta tecnologíaxvi

Las retransmisiones deportivas han sido otro laboratorio en el que experimentar con la realidad aumentada. En 2016, Fox Sports comenzó la temporada de retransmisiones de los partidos de NFL con nuevos grafismos a partir de su empleo. En este acuerdo, también estaban incluidas las firmas Sportvision, que aportaba el seguimiento óptico y sintetizaba la información que facilitaba la cadena a través de su skycam, y Vizrt, el motor gráfico que procesa y produce los gráficos aumentados. Los recursos más habituales consistían en publicar siluetas de jugadores, el posicionamiento en el campo y las estadísticas del partido ${ }^{\mathrm{xvii}}$.

En España, la primera experiencia llamativa de realidad aumentada en televisión corrió a cargo de Fox. En octubre de 2014, la filial española del prestigioso canal de series norteamericano propuso en la Plaza de Callao de Madrid un encuentro con seguidores de series como "The Walking Dead", "Homeland" o "Sleepy Hollow". Gracias a una gran pantalla y al empleo de esta tecnología, los asistentes pudieron interactuar con los personajes de sus series preferidas y protagonizar alguna de sus tramas rodeados de elementos habituales en sus capítulos construidos a partir de tecnología aumentada $3 \mathrm{D}^{\mathrm{xviii}}$.

Pero si ha habido un antecedente significativo en los últimos años para que los canales españoles recogieran el guante tecnológico y aplicaran esta tecnología en su programación, ése es The Weather Channel (The Weather Company). Desde 2015, el canal ha sido premiado por lanzar experiencias en realidad aumentada para presentar contenido relacionado con fenómenos meteorológicos, desastres naturales, etc. ${ }^{\text {xix }}$. Es a partir de abril de 2018 cuando sus acciones se vuelven más espectaculares y llamativas. Esto tiene un motivo fundamental: su acuerdo con la firma noruega The Future Group, pionera en la tecnología interactiva de realidad mixta y las herramientas de desarrollo y software de Unreal Engine, desarrolladas por Epic Games ${ }^{\mathrm{xx}}$. Según Bill Dow ${ }^{\mathrm{xxi}}$, vicepresidente ejecutivo de The Weather Company, la realidad aumentada conseguiría crear el hábito en la audiencia de sintonizar, quedarse y mirar absorto las técnicas de narración del clima, el tráfico o cualquier otro tema cuando se presentan de esa manera. Así se puede apreciar en la siguiente imagen (figura 2): 
Figura 2: Ejemplo realidad aumentada aplicada a la cobertura de información meteorológica

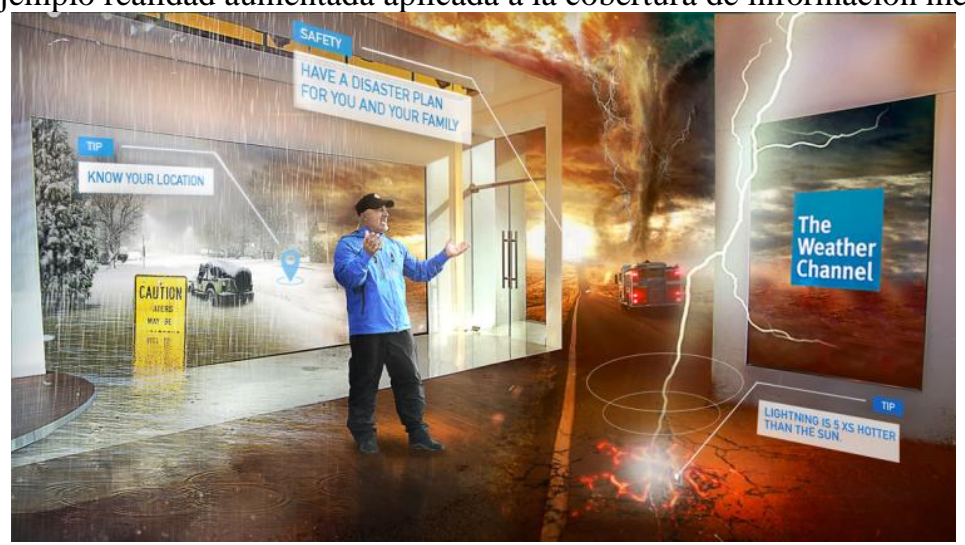

Fuente: The Weather Channel (2019)

\title{
4 RESULTADOS
}

En este contexto, el propósito de este trabajo es realizar una primera aproximación sobre los usos, ventajas, límites y desafíos que supone aplicar la realidad aumentada a la información periodística en televisión. Para ello, además de revisar la literatura académica y profesional sobre el tema, nos hemos basado en el visionado de cerca de 40 ejemplos de medios periodísticos de referencia y en la realización de 6 entrevistas en profundidad a expertos. A continuación, presentamos los resultados estructurados en los principales ejes que configuran este trabajo: usos, ventajas, inconvenientes y desafíos.

\subsection{PRINCIPALES USOS}

De un modo general, Jaime Rull alude a que resulta fundamental que la realidad aumentada, como cualquier tecnología, sirva para aportar un valor añadido, en lugar de ser concebida como un elemento significante en sí mismo (Tejedor, et. al., 2020: 10):

\begin{abstract}
"Partiendo de la concepción de las enormes, casi ilimitadas, posibilidades que ofrece la realidad aumentada en contenidos audiovisuales, si nos circunscribimos al ámbito periodístico habría que tener como absoluta prioridad la de aportar un valor añadido a la información que se quiere transmitir. Y ese valor añadido se traduce en que el receptor de esa información la reciba de una manera inmersiva, que se pueda sumergir en ella de tal manera que la pueda experimentar en una nueva dimensión, no solo en el formato tradicional de un mensaje oral y escrito y un mero apoyo de imagen real en dos dimensiones. Por esta razón, los usos más apropiados de la realidad aumentada en la información periodística podrían centrarse en la explicación visual de datos complejos, en la recreación tridimensional e interactiva de estructuras y elementos del mundo real a escala o a tamaño real o como una evolución lógica y tecnológica de los conceptos clásicos de infografía y de grafismo en televisión y otros medios audiovisuales" (Jaime Rull, 2019).
\end{abstract}

Desde una perspectiva más concreta, César González Antón se refiere al potencial que ofrece esta tecnología para explicar conceptos y procedimientos y para ubicar en qué lugar se produce una información:

"Lo principal es la capacidad pedagógica. Cuando en Atresmedia [Antena 3 y La Sexta] nos 
lanzamos con este sistema, lo que nos pareció fascinante es cómo podríamos hacer eso que tanto hacemos en La Sexta: buscar la parte explicativa del periodismo, ese modelo explainer de YouTube, buscando explicar cómo funciona la economía, el porqué de una situación, o cómo funciona un juicio importante, o qué ha sucedido en un atentado concreto. La realidad aumentada nos daba la oportunidad de ser mucho más pedagógicos. Quizá no tanto lo que veíamos, porque lo que veíamos era más bien espectacular. Veíamos montajes de realidad aumentada muy espectaculares en medios americanos o europeos. Pero no pensábamos en el aspecto espectacular, sino en la vena pedagógica” (César González Antón, 2019).

Encontramos un ejemplo de este uso en la siguiente captura que explica las excavaciones que se llevaron a cabo en enero de 2019 en Totalán (Málaga) para tratar de rescatar el cuerpo de Julen, un niño de dos años que se había caído en un pozo (figura 3):

Figura 3: Ejemplo de aplicación de realidad aumentada para explicar procedimientos

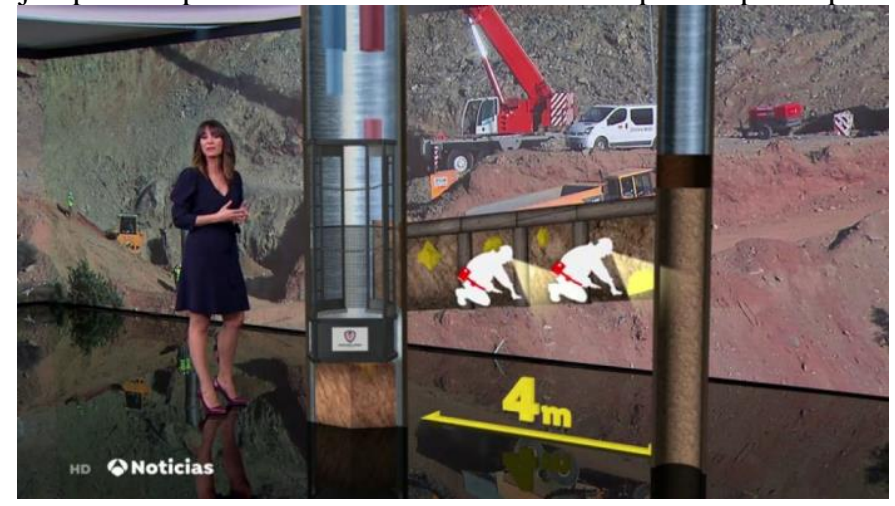

Fuente: Antena 3 TV (2019)

Esteban Galán suma el potencial que ofrece esta tecnología para visualizar datos e información geolocalizada:

"Podemos conseguir que el formato de presentación de contenido sea el propio lugar donde sucedió la noticia. A través de paseos guiados, tours o simplemente a través de fotografías del lugar, podemos insertar diferentes capas de información” (Esteban Galán, 2019).

Por su parte, Borja Terán añade la posibilidad que ofrece esta tecnología para mejorar la escenografía:

"Yo creo que el periodismo es siempre enriquecer el relato. El diseño ha sido crucial para hacer accesible el contenido. En eso, la realidad aumentada favorece. Cuando sirve para divulgar mejor, para dar perspectiva y contexto, será bienvenida. Podrán hacerse gráficos atractivos o explicar determinadas situaciones, aportar una mirada atractiva, más fácil de digerir al espectador o al usuario en las redes, y un golpe de atención” (Borja Terán, 2019).

\subsection{PRINCIPALES VENTAJAS}

Para Jaime Rull, una de las principales ventajas que ofrece la realidad aumentada reside en su atractivo visual, algo que permite captar la atención de un modo muy natural: 
"El innegable atractivo visual que ofrece al espectador logra de él una especial atención, una concentración de sus sentidos hacia la pantalla y al emisor de la información que, en estos tiempos de dispersión y desconcentración mental, lo hacen especialmente valioso para ambas partes: para el creador de un contenido, el transmisor de una información y para su receptor y destinatario. Un envoltorio 'premium' para un cliente que anhela sentirse especial, diferenciado" (Jaime Rull, 2019).

Siguiendo a González Antón, esta necesidad de apelar a la atención del espectador de un modo constante resulta más urgente en televisión que en otros medios:

"La televisión necesita captar la atención constantemente. El mando a distancia es un camino a la infidelidad. La realidad aumentada es una herramienta que es muy pedagógica y que además es muy espectacular. Permite captar la atención al espectador porque ofrece un formato al que no está acostumbrado. Y porque visualmente es capaz de entender algo gráficamente: por ejemplo, dónde está la tumba de Franco, o los tipos de armas que está vendiendo cualquier país" (César González Antón, 2019).

Además, varios entrevistados coinciden en que el empleo de esta tecnología permite comprender de manera más profunda la realidad sobre la que se está informando:

“(..) emplear elementos 3D que permitan al usuario entender el mensaje o noticia de un modo más profundo que si se realiza en 2D. El sesgo de interpretación en contenidos 2D es mucho mayor que sobre elementos 3D realistas. Contar una noticia delante del espectador, no con imágenes 2D, sino como si fuera una maqueta 'viva' donde se desarrolla la noticia” (Eduardo Herranz, 2019).

En este mismo sentido, Laura Raya añade que las realidades extendidas favorecen una mayor inmersión:

\begin{abstract}
"Las realidades extendidas potencian enormemente la sensación de presencia frente a otras alternativas audiovisuales. Permiten al espectador vivir la noticia desde dentro, provocan un mayor grado de empatía ante los implicados de la noticia, mayor asimilación del hecho y, probablemente mayor entretenimiento para seguir consumiendo noticias. La realidad aumentada, virtual o mixta supone una nueva forma de representación de la información, más atractiva, inmersiva y completa. Es el nuevo medio audiovisual que se extenderá durante los próximos años y viviremos un cambio tan drástico como el que experimentamos de la radio a la televisión. Podemos hablar de realidad aumentada no virtual en CG; es decir, con contenido generado por ordenador (modelos, animaciones, etc.) o podemos hablar de vídeo 360 estereoscópico y volumétrico, lo que puede revolucionar totalmente la manera de visualizar las grabaciones de las noticias o entrevistas y debates" (Laura Raya, 2019).
\end{abstract}

Esteban Galán añade que el empleo de esta tecnología permite incluso empoderar al usuario:

"Fundamentalmente empodera al usuario porque le ofrece una capa interactiva que además es natural. En un momento en el que la realidad física y la realidad digital cada vez están más conectadas (gran parte de lo que sucede en nuestro día a día sucede dentro de una pantalla), es imprescindible contar con formatos para contar historias que permitan juntar esas dos realidades. La realidad aumentada no hace otra cosa que reproducir parte de lo que ya está pasando en nuestras vidas” (Esteban Galán, 2019). 
Para Borja Terán, el potencial que ofrece esta tecnología para dinamizar la escaleta no resulta una ventaja menor:

"La realidad aumentada puede servir de mucho, por ejemplo, en la escenografía y hacer que un plató de informativos tenga más profundidad y mejorar el relato (...). La realidad aumentada será importante cuando aporte, sea sostenible, cuando valga. Y será útil en dos situaciones: para clarificar un dato, un contexto, siempre va a ser útil (...) Y, en segundo lugar, para romper el ritmo en programas largos, para no hacer tan aburrida una información” (Borja Terán, 2019).

\title{
4.3 PRINCIPALES LÍMITES
}

El principal límite en el que coinciden los entrevistados es el coste económico que, a su vez, se refiere tanto a los recursos técnicos que demanda elaborar estas piezas - por la instalación en plató, software y hardware - como a la formación necesaria para cualificar a los equipos. Laura Raya apunta otro inconveniente ante las dificultades de contar exclusivas a través de esta tecnología, habida cuenta del tiempo que requiere su elaboración. Por su parte, Esteban Galán alude a la falta de estandarización de la tecnología que impide que el usuario pueda disfrutar de todo el potencial que ofrece. Borja Terán alerta de la posibilidad de que esta tecnología llegue a "aburrir" por reiterativa:

"El problema es que a veces el espectador ya es inmune a ese golpe de efecto o de atención. Que aparezca Downing Street en el informativo de Antena 3 varias veces ya no interesa al espectador. Son fuegos artificiales que no interesan y no son fundamentales para el informativo. El peligro es hacer al espectador inmune a ese golpe o llamada de atención” (Borja Terán, 2019).

Para César González Antón, la propia espectacularidad que permite esta tecnología sería al mismo tiempo uno de sus principales límites:

\begin{abstract}
"La realidad aumentada tiene una trampa, que es perder el carácter informativo por pecar de espectacularidad. Nosotros vimos cosas espectaculares en Estados Unidos, como por ejemplo los efectos de un huracán en plató. Es muy caro de hacer y muy espectacular. Pero informativamente no tiene tanto valor. Tienes el riesgo de emborracharte de realidad aumentada para nada. De llenar el plató de cosas muy espectaculares que luego no estén contando nada. Y el riesgo de convertir el tiempo del espectador en tiempo perdido. Porque alguien puede ver una gran producción de realidad aumentada, pero al terminar no haber aprendido nada. Ése es el gran inconveniente, saber cómo no perder el norte y ser útil al espectador y no ser espectacular para no contar nada" (César González Antón, 2019).
\end{abstract}

Asimismo, los entrevistados apuntan a la falta de formación y de personal cualificado en las salas de redacción dada la novedad y complejidad técnica que demanda esta tecnología.

\subsection{PRINCIPALES DESAFÍOS}

En cuanto a los desafíos que supone aplicar realidad aumentada a la información periodística en televisión, el director de informativos de La Sexta plantea 2: 
"Supone dos grandes desafíos. El primero de formación: formación de grafismo. Ser capaces de sacar el partido que tiene la herramienta. Nosotros tenemos un equipo que se ha formado en foros, con manuales y que tiene una gran capacidad de aprender de forma autodidacta. Pero el desafío es inmenso porque queda mucho que aprender. Y, además, implica un desafío sobre el trabajo del periodista. El periodista, grafista y realizador deben trabajar juntos. Son un equipo con conceptos periodísticos. Si tienes una idea periodística pero el resto del equipo (grafista y realizador) no tienen el concepto, no saben entenderla, no va a salir bien. Y, por el contrario, si tienes dos grandes técnicos, con capacidad brutal, pero el periodista no sabe contar el hecho, tampoco será útil. Hemos visto grandes producciones en otras televisiones que no aportaban valor informativo" (César González Antón, 2019).

Los entrevistados coinciden en señalar otros desafíos como la necesidad de dedicar recursos para adaptar los platós y las redacciones y la de formar a los equipos ya que el empleo de esta tecnología requiere "nuevos sistemas de captura, que no son precisamente baratos, ni sencillos de operar" (Eduardo Herranz, 2019).

En un sentido más general, otros entrevistados se refieren al enorme reto que supone cambiar el proceso de producción de la información, pero también la nueva forma de consumo:

\begin{abstract}
"Requiere, para empezar, un cambio de mente completo de cómo presentar una noticia. Un cambio de guion, de montaje y de alcance de la noticia. Un cambio psicológico de cómo impactar al espectador. Ya no es tan necesario utilizar tanto desarrollo narrativo para trasladar al espectador la situación de uno de los sucesos. Ahora puede vivirlos o estar en la escena del crimen grabada en vídeo 360. Plantea el desafío de que haya más gente capaz de generar el contenido a través del manejo de la tecnología. Requiere más programadores y más expertos en realidades extendidas. Por supuesto, requiere la capacidad económica de las cadenas y medios de invertir en una nueva forma de representación de la información innovadora e inmersiva y requiere que los ciudadanos cuenten con tecnologías que les permitan consumir la noticia de esa manera" (Laura Raya, 2019).
\end{abstract}

En este punto, Eduardo Herranz se refiere a que siempre es necesario emplear la tecnología con un propósito concreto, "no sólo como elemento novedoso que no aporte valor", evitando caer en el simple "postureo". Esteban Galán añade el desafío de gamificar el entorno para que resulte intuitivo y amigable:

"El desafío fundamentalmente entiendo que es filosófico, conceptual. Ya no estoy creando una representación de la realidad a través de un formato visual, audiovisual, sonoro etc. sino que estoy añadiendo capas de contenido sobre la propia realidad y lo estoy haciendo además de forma que permite al usuario que interactúe; es decir, que juegue con esa realidad y la explore (como ya hicimos en la infancia). Esto conecta directamente los medios de comunicación con los videojuegos porque es necesario gamificar ese entorno para que sea intuitivo y amigable. Por otra parte, abre el reto de cómo incentivar la participación y la co creación de contenidos por parte del usuario en esos nuevos formatos" (Esteban Galán, 2019).

\title{
5 CONCLUSIONES
}

Aplicada a la información periodística en televisión, la realidad aumentada ofrece un gran potencial para contenidos de carácter explicativo y para ubicar el escenario en el que se produce la información. A su vez, la propia existencia de ventajas e inconvenientes subraya el carácter instrumental 
de esta tecnología y la necesidad de emplearla con un propósito concreto y con un criterio periodístico que aporte valor añadido, mejore el relato y presente la información de un modo más visual y espectacular.

Los usos más apropiados para aplicar realidad aumentada a la información periodística se refieren a la posibilidad de explicar conceptos y procedimientos, recrear elementos gráficos, ubicar dónde sucede la información, mostrar escenarios relevantes, mejorar la escenografía y permitir visualizar datos geolocalizados.

Convenientemente empleada, esta tecnología ofrece importantes ventajas como la de aportar un valor añadido a la información, servir como una herramienta pedagógica, ofrecer un mayor atractivo visual, favorecer la inmersión, permitir captar la atención del espectador y dinamizar la escaleta del informativo.

En la actualidad, los inconvenientes más evidentes que presenta se refieren a su coste económico -tanto en recursos como en la formación que requiere cualificar equipos multidisciplinares-, a la propia falta de formación técnica para utilizar los equipos y al peligro de perder el criterio periodístico ante el mayor peso que se le pudiese otorgar a la parte más técnica. Además, la realidad aumentada no permite contar exclusivas porque la producción de las piezas requiere de un tiempo mayor que el que se precisa para diseñar un gráfico más básico en dos dimensiones. Conviene también tener en cuenta que la realidad aumentada podría llegar a aburrir al espectador por reiterativa, lo que aconseja utilizarla de modo intencional y con un propósito muy claro, concreto y específico.

Como resultado de estos inconvenientes, el empleo de esta tecnología plantea importantes desafíos. Uno de los más evidentes se refiere a la necesidad de dedicar recursos para adaptar los platós y las redacciones, formar a los equipos de grafismo, ajustar de un modo eficiente el criterio periodístico y el técnico, cambiar el proceso de producción de la información y emplear la tecnología con un sentido concreto que evite que quede reducida a un mero ejercicio de estilo. En todo caso, siguiendo a Tejedor et. al (2020: 9), es muy posible también que la tecnología 5G -con sus mejoradas velocidad de navegación y latencia- impulse definitivamente la realidad aumentada consiguiendo que su aplicación al periodismo resulte cada vez menos excepcional. 


\section{REFERENCIAS}

Abascal, J. et al. (2001). La interacción persona-ordenador, disponible en: http://speedbooksargentina.blogspot.com/2010/02/la-interfaz-persona-ordenador.html [Consulta: 22/03/2019].

Abril, D. (2012). Realidad aumentada. Madrid: Universidad Carlos III de Madrid, disponible en https://docplayer.es/13405952-Realidad-aumentada-daniel-abril-redondo-universidad-carlos-iii-demadrid-leganes-100055498-alumnos-uc3m-es-resumen-2.html [Consulta: 20/03/2019].

Asensi, E. (2016). La evolución tecnológica en los sistemas de producción de noticias televisivas. De Antena 3 a Atresmedia. Tesis Doctoral defendida en la Universidad Cardenal Herrera-CEU, disponible en: http://dspace.ceu.es/handle/10637/8385 [Consulta: 21/03/2019].

Azkunaga, L, Gaztaka, I. y Eguskiza, L. (2019). Nuevas narrativas en televisión. La realidad aumentada en los telediarios de Antena 3. Revista de Comunicación, 18, 2, 25-50.

Azuma, R. (1997). A survey of Augmented Reality. Presence: Teleoperators and Virtual Environments, 6, 4, 355-385, disponible en: https://doi.org/10.1162/pres.1997.6.4.355

Caldera-Serrano, J. (2014). Realidad aumentada en televisión y propuesta de aplicación en los sistemas de gestión documental. El profesional de la información, 23, 6, 643-650, disponible en:

https://recyt.fecyt.es/index.php/EPI/article/view/epi.2014.nov.12

Caudell, T.P. y Mizell, D.W. (1992). Augmented Reality: An Application of Heads-Up Display Technology to Manual Manufacturing Processes. Actas de la XXV Conferencia Internacional de Hawai, 2, 659-669. DOI: 10.1109/HICSS.1992.183317

Galán Cubillo, E. (2008). Escenografía virtual en TV. Análisis del uso de escenografía virtual en la realización de un programa de televisión. Revista Latina de Comunicación Social, 63, 31-42. DOI: 10.4185/RLCS-63-2008-752-031-042

Meneses Fernández, M.D. y Martín Gutiérrez, J. (2013). Realidad aumentada e innovación tecnológica en prensa. La experiencia de ver y escuchar un periódico impreso. Estudios sobre el mensaje periodístico, 19, 1, 207-221, disponible en: http://dx.doi.org/10.3989/arbor.2016.777n1008 [Consulta: 21/03/2019].

Milgram, P. y Kishino, F. (1994). Taxonomy of mixed reality visual displays. IEICE Transactions on Information Systems, E77D, 12, 1321-1329.

Parra, D., Edo, C. y Marcos, J.C. (2017). Análisis de la aplicación de las tecnologías de realidad aumentada en los procesos productivos de los medios de comunicación españoles. Revista Latina de Comunicación Social, 72, 1670-1688. DOI: 10.4185/RLCS-2017-1240

Pavlik, J.V. y Bridges, F. (2013). The Emergence of Augmented Reality as a Storytelling Medium in Journalism. Journalism \& Communication Monographs, 151, 4-59, disponible en: https://doi.org/10.1177/1522637912470819_[Consulta: 22/03/2019].

Picón Masero, H. (2014). La realidad aumentada aplicada al periodismo impreso. Trabajo Fin de Grado defendido en la Facultad de Comunicación de la Universidad de Sevilla, disponible en: http://hdl.handle.net/11441/30548 [Consulta: 21/03/2019]. 
Pellicer Jordá, M.T. (2013). La importancia de la tecnología para el ámbito de la comunicación. Historia y Comunicación Social, 18, 481-489, disponible en:

https://doi.org/10.5209/rev_HICS.2013.v18.43982_[Consulta: 22/03/2019].

Prendes-Espinosa, C. (2015). Realidad aumentada y educación: análisis de experiencias prácticas. Pixelbit. Revista de medios y educación, 46, 187-203.

Richeri, G. (1994). La transición de la televisión. Barcelona: Bosch Comunicación.

Sanz, L. (2006). La influencia de la tecnología en la televisión. BIT (Boletín Informativo de Telecomunicación), 50-52, disponible en: https://www.coit.es/servicios/publicaciones/revista-bit

Tejedor, S. et. al (2020). Periodismo que cuenta el futuro: posibilidades y escenarios periodísticos para la realidad aumentada. El profesional de la información, 29, 6, disponible en http://profesionaldelainformacion.com/contenidos/2020/nov/tejedor-romero-moncada-alencar_es.pdf [Consulta: 11/12/2020].

Túñez, M., Martínez, Y. y Abejón, O. (2010). Nuevos entornos, nuevas demandas, nuevos periodistas. Estudios sobre el mensaje periodístico, 16, 79-94, disponible en: https://revistas.ucm.es/index.php/ESMP/article/view/ESMP1010110079A_[Consulta: 21/03/2019].

\footnotetext{
${ }^{\mathrm{i}}$ https://www.theguardian.com/media/pda/2010/jan/06/journalism-augmented-reality [Consulta: 29/05/19]

ii https://www.youtube.com/watch?v=LGwHQwgBzSI [Consulta: 29/05/19]

iii https://www.elmundo.es/elmundo/2009/11/02/comunicacion/1257159053.html [Consulta: 29/05/19]

${ }^{\text {iv }}$ media.wallpaper.com/pdf/WallpaperJan2010.pdf [Consulta: 30/05/19] y https://www.dexigner.com/news/19672 [Consulta: 30/05/19]

${ }^{\mathrm{v}}$ https://www.youtube.com/watch?v=VIC1sqT33X8 [Consulta: 30/05/19]

${ }^{\text {vi }}$ https://www.youtube.com/watch?v=YJtkOk685Uw [Consulta: 29/05/19]

vii https://elviajero.elpais.com/elviajero/2010/04/26/actualidad/1272274444_850215.html [Consulta: 29/05/19]

viii https://www.youtube.com/watch?v=5TUB2hbsD7Y [Consulta: 29/05/19]

ix https://www.youtube.com/watch?v=v8eXlcy1TyU [Consulta: 30/05/19]

${ }^{\mathrm{x}} \mathrm{http}$ ://popsop.com/2010/03/calvin-klein-employs-augmented-reality-to-promote-its-new-underwear-in-gq/ [Consulta: 30/05/19]

${ }^{x i}$ https://www.youtube.com/watch?v=oy7coM7IMq4 [Consulta: 30/05/19]

xii https://www.youtube.com/watch?v=fv71Pe9kTU0 [Consulta: 29/05/19]

xiii https://www.youtube.com/watch?v=iEmk6PmC1Hc [Consulta: 29/05/19]

${ }^{\text {xiv }}$ http://www.jacktsai.me/augmented-reality-for-news.html [Consulta: 29/05/19]

${ }^{\mathrm{xv}}$ https://www.youtube.com/watch?v=itscUNAqbLQ [Consulta: 30/05/19]

${ }^{\mathrm{xvi}} \mathrm{https}: / / \mathrm{www}$. youtube.com/watch?v=CgaaLgf0Bcc [Consulta: 30/05/19]

xvii https://www.youtube.com/watch?v=sFblcUFbsCQ [Consulta: 30/05/19]

xviii https://www.youtube.com/watch?v=Bj-RbEurkBE [Consulta: 29/05/19]

${ }^{\text {xix }} \mathrm{https}$ ://business.weather.com/blog/augmented-reality-transforming-the-weather-forecast [Consulta: 29/05/19]

${ }^{\mathrm{xx}}$ https://www.youtube.com/watch?v=69nUZmQ2w8A [Consulta: 29/05/19]

${ }^{x x i}$ https://ar-vr.cioreview.com/cxoinsight/augmented-reality-transforms-broadcast-industry-nid-13684-cid-135.html [Consulta: 30/05/19]
} 